The Research Journal of the Costume Culture

[Original Article]

Received January 18, 2017

Accepted February 27, 2017

${ }^{\dagger}$ Corresponding author

(khlee@hanyang.ac.kr)

ORCID

JEE-SUN PARK

http://orcid.org/0000-0002-6021-2836

So Won Jeong

http://orcid.org/0000-0002-8411-152X

Kyu-Hye Lee

http://orcid.org/0000-0002-7468-0681

\section{Effects of K-drama on attitudes of Chinese consumers toward Korean fashion products \\ - The role of perceived similarity and people image -}

\author{
Jee-Sun Park, So Won Jeong ${ }^{*}$ and Kyu-Hye Lee ${ }^{\dagger * *}$
}

Dept. of Fashion Industry, Incheon National University, Korea

Dept. of Clothing \& Textiles, Sangmyung University, Korea*

Dept. of Clothing \& Textiles, Hanyang University, Korea ${ }^{* *}$

\section{중국 소비자들의 한국 TV드라마 시청이 한국 패션제품 태도 형성에 미치는 영향 - 드라마 등장인물과의 유사성과 국민이미지 역할을 중심으로 -}

\author{
박지선 · 정소원 ${ }^{*}$ 이규혜 ${ }^{*+}$ \\ 인천대학교 패션산업학과, 상명대학교 의류학과*, 한양대학교 의류학과**
}

\begin{abstract}
As the popularity of Korean drama and celebrities in China, Korean fashion is becoming increasingly popular in the Chinese market. Although the effect of Korean drama on Chinse consumers' attitudes toward Korean products are known, little research has been conducted to understand the mechanisms underlying the impact of Korean drama on the development of consumer attitudes. Thus, this study examines how Chinese consumers' exposure to Korean dramas has influenced their attitudes towards Korean fashion products. Applying the similarity-attraction theory, the study explores the roles Chinese consumers' perceived similarities in appearance and values with Korean characters in TV dramas plays in the process of attitude development. Data was collected via an online survey and the responses of 317 Chinese consumers in their twenties were used for data analysis. The results of structural equation modeling show that exposure to Korean dramas has a direct impact on Chinese consumers' perceived appearance similarity, perceived value similarity, image of Korean people, and attitudes toward Korean fashion products - results that support the theory of mere exposure. In addition, the analysis demonstrates that perceived appearance similarity positively influences the image of Koreans among Chinese people, which, in turn, influences attitudes toward Korean fashion products, supporting the similarity-attraction theory. However, the effect of perceived value similarity on attitude toward Korean fashion products was not significant. The study concludes by describing its practical implications for the Korean fashion industry and presenting ideas for future research.

Keywords: Korean drama(한국 드라마), Chinese consumers(중국 소비자), perceived similarity (지각된 유사성), people image(국민 이미지), attitudes toward fashion products(패션제품태도)
\end{abstract}




\section{Introduction}

13 억명이 넘는 중국 소비자들의 향상된 소비생활 은 세계 고가 제품 시장뿐 아니라, 다양한 중저가 제 품 시장 형성에 기여하였다. 세계 소비 시장에서 중 국의 경제정책 및 그에 따른 중국 소비자의 반응은 세계 시장에 큰 영향을 미치는 중요 요소로 작용한다 (Castro, 2015; Russo, 2015). 중국의 개인 소비자들은 세계적 경제불황 및 최근 급변하는 자국 주식시장 및 통화정책에도 비교적 안정적인 소비성향 및 소비행 태를 보여주며(Mulligan, 2015), 세계시장에서 그 영 향력을 보여준다. 특히, 중국의 고가 의류 시장을 비 롯한 패션잡화 시장의 경우, 세계적 경제불황 및 중 국 자체의 성장둔화에도 불구하고, 높은 성장률을 보 이고 있다(He, Ling, \& Li, 2013; Sun, 2015). 특히 자 아만족을 위한 외모 관리를 위한 소비 분야를 지칭하 는 허영심(vanity) 소비 분야에서는 지난 5 년 동안 $15.6 \%$ 의 높은 성장률을 기록하고 있다(Kuo, 2015). 이와 같은 현상은 패션 관련 기업들에게 중국이 매우 매력적인 시장임을 보여준다.

매력적인 만큼 더욱 치열해지는 중국의 패션시장 에서 한국 브랜드는 중국 소비자들이 한국 및 한국제 품에 대하여 비교적 호의적인 평가를 보이는 상황에 있으며(Kim \& Park, 2004; Lim, Lee, \& Kim, 2013), 중국 소비자들의 한국 패션에 대한 관심은 온라인 구 매 및 한국 방문 쇼핑으로 이어지고 있다. 중국 소비 자들의 한국 제품에 대한 호의적인 태도는 90 년대 이 후 지속된 한류의 영향이 존재한다. 이에 대해 많은 선행연구들은 한류로 인한 국가 이미지 상승이 한국 제품에 대한 태도 형성에 영향을 주는 것을 보여주 며, 한류의 후광효과로 설명하였다(Hwang, Kim, \& Ahn, 2008; Kwon, Hong, Seo, \& Cho, 2009; Moon, 2014; Yang, Kim, \& Rhee, 2012). 특히 한국 패션, 뷰 티 및 관광상품은 관련주가가 급상승한 것으로도 알 수 있듯이, 패션은 한류의 최대 수혜상품 중 하나라 고 할 수 있을 것이다(Tang, 2015).

한류에 대한 선행 연구는 한류 문화콘텐츠, 그 중 에서도 한국 TV드라마가 외국 소비자들의 한국 및 국내제품에 대한 긍정적인 이미지 형성에 영향을 미 친다는 것을 보여준다(Jun \& Zhang, 2012; Yoo, 2007). 즉, 중국 소비자들의 한국 드라마 노출과 드라마를
통한 한국 문화 및 제품에 대한 간접적인 경험은 한 국에 대한 이미지 형성에 영향을 주게 되며, 형성된 이미지는 한국 제품 및 브랜드에 대한 이미지로 이어 지는 것이다. 한국 대중문화의 노출 또는 한류의 영 향에 따른 경제적 효과를 보여준 선행연구는 비교적 많은 반면(Kim \& Ahn, 2012), 중국 소비자들의 한류 콘텐츠 소비가 국가 이미지 또는 한류 관련 상품에 미치는 영향에서 소비자들의 인지 과정에 대한 연구 및 설명은 부족한 실정이다. 따라서 중국 소비자들의 한국 대중문화 경험에 따른 소비자들의 심리적인 반 응과 이러한 심리적인 반응을 통한 한국 패션 상품에 대한 태도 형성 과정에 대한 연구가 필요하다.

패션제품은 자아 표현 도구 중 하나로서 개인이 지 각하는 자신의 이미지와 연관성이 높고(Kaiser, 1997; Lee, 2009), 개인의 의복행동은 자신이 추구하는 신 체에 대한 이미지(Hwang, 1998) 및 개인의 가치관(Kim \& Lee, 1992; Lim, Lim, \& Jo, 1995)에 영향을 받게 된다. 따라서 TV드라마 등장인물의 신체 이미지뿐 아 니라, 등장인물의 역할에 따른 개인 성향이 반영되어 제시되는 패션제품은 착용자의 이미지와 함께 평가 될 것이다. 즉, 한국 드라마 시청으로 인한 중국 소비 자들의 한국 패션제품에 대한 태도 형성의 과정에는 드라마에 등장한 인물들에 대한 신체적 또는 가치관 에 대한 인식에 대한 반응이 있을 것이며, 등장 인물 에 대한 인식은 한국인에 대한 평가에도 영향을 줄 수 있을 것이다. 이에 본 연구는 중국 소비자들의 한 국 드라마 시청이 한국 패션제품에 대한 태도 형성에 미치는 영향에 대한 설명력을 높이기 위하여, 중국 소비자들의 심리적 인지과정 중 한국 드라마의 등장 인물 및 한국 국민에 대한 인식의 역할을 알아보고자 하였다.

\section{Theoretical Background}

\section{Korean TV drama}

TV드라마는 등장배경과 함께 등장인물들의 일상 생활과 같은 모습을 연속적으로 보여줌으로 시청자 들은 그 등장인물이 사는 매일의 삶을 보는 것과 같 은 느낌을 받는다(Su, Huang, Brodowski, \& Kim, 2011). 따라서 드라마는 등장인물의 라이프스타일을 보여주 고 사회 이미지를 투영함으로, 하나의 생활상을 제시 
및 정립하는 영향력 있는 채널 중 하나라고 할 수 있 다. 특히 시청자들은 외국 TV드라마를 통해 그 사회 에 대한 다양한 사회 생활상과 이국적이고 다양한 라 이프스타일을 쉽게 접할 수 있으며(Xu, 2007), 드라마 는 시청자들의 외국 생활에 대한 학습에 큰 역할을 하 게 된다(Jiang \& Leung, 2012).

한국 드라마에 대한 연구를 보면, 한국 드라마는 사 랑을 바탕으로 아름다운 세계를 지향하며 이상적인 주 인공들과 함께 사실적 재현보다는 정서적 전달을 통한 감정적 공감을 일으킨다는 특징을 보인다(Choi, Lim, \& Meng, 2012; Jiang \& Leung, 2012; Kim et al., 2009). 한국 드라마의 이러한 특징은 중국의 중산층 여성들에 게 특히 공감을 불러일으키며, 드라마를 통한 현대적 인 라이프스타일에 대한 감각을 고양시키는 데 이용 되기도 한다(Jiang \& Leung, 2012).

중국 소비자들의 개인 성향에 따른 드라마 소비 행 동을 보면, 유행지향적이며 의견 선도력이 있는 시청 자들에게 한국 드라마는 사회화의 도구로 이용되는 경 향을 관찰할 수 있다(Jiang \& Leung, 2012). 즉, 중국 소비자들은 한국 TV드라마를 통하여 현대 패션, 외 국 문화, 또는 외국 라이프스타일을 간접경험하고 생 활습관을 현대화하며, 이 과정을 통하여 사회의 다른 구성원들과 자신의 차별성을 보여주며, 사회적 인지도 를 얻고자 하는 경향을 보인다(Jiang \& Leung, 2012; $\mathrm{Xu}, 2007)$.

\section{Attitudes toward Korean fashion products}

태도는 개인이 특정 대상에 대하여 가지는 전반적 인 감정으로 개인의 행동을 예측할 수 있는 중요한 변 수로 제시되었으며, 많은 선행연구에서 이를 검증하 였다(Bagozzi, 1981; Petty \& Cacioppo, 1981). 즉, 소 비자 개인이 특정 제품 또는 브랜드에 대한 호의적인 감정이 높을수록 그 제품과 브랜드 구매 또는 긍정적 인 구전행동 등의 다양한 행동으로 이어질 가능성이 높아지게 된다.

한국 패션제품에 대한 태도는 소비자 개인이 한국 패션제품에 대하여 가지는 전반적인 감정을 뜻한다. 선행 연구는 외국 소비자들의 한국 TV드라마 시청이 한국제품에 대한 긍정적인 태도 형성에 영향을 미친 다는 것을 보여준다(Yoo, 2007; Jun \& Zhang, 2012). 이 현상은 단순노출효과이론(mere exposure theory)
(Zajonc, 1968, 2001)에 의해서 설명될 수 있다. 즉, 사람들은 반복적으로 노출된 대상에 대하여 긍정적 인 이미지를 가지게 되며(van Reijmersdal, Neijens, \& Smit, 2007), 이렇게 노출된 제품은 그 제품에 대한 믿 은 또는 태도가 형성되기 전이라도 소비자들로 하여 금 친숙하게 느껴지게 하며, 호의적인 이미지 형성에 영향을 주게 된다(Hekkert, Thurgood, \& Whitfield, 2013).

TV드라마는 일상생활을 반영한 스토리를 제시하 여 시청자들에게 보다 친숙하고 쉽게 접근한다. 따라 서 TV드라마를 통한 제품의 노출은 광고주들로 하여 금 보다 더 구체적이고 세련된 방식으로 제품 광고를 할 수 있게 한다(Karrh, McKee, \& Pardun, 2003). TV 드라마에 노출된 한국 패션제품은 배경, 등장인물 및 스토리에 따라 소품, 등장인물의 화장법 및 의류가 선 택되어 시청자에게 제시되므로, 시청자들에게는 노출 된 제품이 연상작용에 따른 친숙성의 효과로 보다 생 생하게 시청자의 머리속에 남아있게 된다(Busselle \& Shrum, 2003; Shrum \& O'Guinn, 1993). 특히 패션제 품은 드라마 주인공의 역할 및 배경과 관련성이 높아, 드라마에 가장 많이 노출되는 제품 중 하나로서 드라 마 시청 빈도에 영향을 받게 된다(Jun \& Zhang, 2012). 따라서, 단순노출효과이론(Zajonc, 1968, 2001) 및 선 행연구(Hekkert et al., 2013; Jun \& Zhang, 2012)를 바탕으로 다음과 같은 과정을 가정할 수 있다. 한국 $\mathrm{TV}$ 드라마에 빈번하게 노출되는 소비자일수록 드라 마를 통해 한국 패션 스타일 및 브랜드에 자주 노출 이 될 것이며, 이는 한국 패션 스타일 및 브랜드 등을 포함한 전반적인 한국 패션제품에 대한 호의적인 태 도를 형성하는 데 영향을 줄 것이다.

$\mathrm{H} 1$ : 한국 TV드라마 시청은 중국 소비자들의 한국 패션제품에 대한 태도에 정(+)의 영향을 미칠 것이다.

\section{Perceived similarity}

지각된 유사성(perceived similarity)은 대인간 커뮤 니케이션에서 상대방에 대하여 느껴지는 유사함의 정 도를 의미한다(Rogers, 2005; Rogers \& Bhowmik, 1970). 본 연구에서 지각된 유사성이란 중국 소비자들 이 한국 TV드라마에 나오는 한국인 등장인물들과 유 사하다고 느끼는 정도를 말한다. 커뮤니케이션 이론 
에 따르면, 대인간 커뮤니케이션에서 지각되는 유사 성이 높을수록 보다 효과적인 커뮤니케이션이 이루어 진다(Rogers, 2005). 사회적 관계에서 유유상종 효과 를 쉽게 발견할 수 있듯이, 사람들은 본인이 관계를 지속하는 사람들과 인구통계학적인 특성 또는 가치에 있어서 유사한 점을 발견하곤 한다(Gilly, Graham, Wolfinbarger, \& Yale, 1998). 지속되는 상호작용이 이 루어지는 관계는 일반적으로 유사한 성향 사이에서 효과적인 커뮤니케이션이 이루어지기 때문이다.

본 연구에서는 대인간 커뮤니케이션에서 지각된 유사성 효과 이론(Rogers, 2005; Rogers \& Bhowmik, 1970)을 한국 드라마의 등장 인물들과 중국 시청자들 사이에서의 TV드라마를 통한 커뮤니케이션 상황에 적용하였다. 커뮤니케이션 상황에서 상대방에 대하여 느끼는 유사성은 인구통계학적 특성뿐 아니라, 외형 적 특징 및 가치관을 비롯한 다양한 특성에서 지각되 는 개인의 주관적 평가이다(Rogers, 2005). TV드라마 의 등장인물에 대한 판단은 매체에서 보여지는 등장 인물들의 외형적 특징 및 스토리를 통해서 느껴지는 가치관이 위주가 될 것이다. 즉, TV드라마를 통한 커 뮤니케이션에서 중국 소비자들은 등장하는 한국인들 에 대해서 외모 및 가치관에 대해서 인지를 할 것이 다.

사람들은 교류하고자 하는 커뮤니케이션 상대방을 자유롭게 선택할 수 있는 상황에서 유사성이 높은 상 대방을 선택하는 경향이 있으며(Rogers, 2005), 지각 된 유사성이 클수록 서로 잘 통한다고 느끼게 되어 커 뮤니케이션이 보다 활발하게 촉진되고, 정보의 교류 도 더욱 활발히 이루어지는 경향이 있다(Makela, Kalla, \& Piekkari, 2007; McCrosky, Richmond, \& Daly, 1975). 즉, 한국 TV드라마를 통한 활발한 커뮤니케이 션의 지표 중 하나인 시청량은 중국 시청자들이 느끼 는 드라마 등장인물과의 유사성과 관계가 있을 것이 다. 또한 한국 TV드라마를 선호하는 중국 시청자들 은 한국 TV드라마 스토리 및 등장인물들과의 감정적 연대 및 공감을 추구하는 경향이 있듯이(Choi et al., 2012; Jiang \& Leung, 2012), 한국 드라마를 자주 보는 중국 소비자들은 그렇지 않은 소비자들에 비해서 등장 인물들과의 유사성을 인식하고, 친숙함을 느낄 것이라 가정할 수 있다. 더욱이, 단순노출효과 이론(Zajonc, $1968,2001)$ 에 따르면, 반복된 노출에 대하여 사람들
은 노출된 대상의 외형에 대해서 보다 친숙하고 익숙 하게 느끼게 된다. 즉, 한국 드라마를 자주 접하는 중 국 소비자들은 그렇지 않은 소비자들에 비하여 드라 마에 등장한 한국인들과의 외모 및 가치관에 대해서 유사성을 보다 많이 느낄 것이다. 따라서 다음의 가 설을 제시할 수 있다.

$\mathrm{H} 2$ : 한국 TV드라마 시청은 지각된 외모 유사성에 정 $(+)$ 의 영향을 미칠 것이다.

$\mathrm{H} 3$ : 한국 TV드라마 시청은 지각된 가치 유사성에 정 $(+)$ 의 영향을 미칠 것이다.

\section{People image}

이미지는 어떤 대상에 대해서 개인이 형성하는 신 념이나 인상 등을 토대로 한 집합적인 상으로서, 국민 이미지는 특정국가의 국민들에 대해서 개인이 가지 는 인상이나 믿음의 총체이다. 국민이미지는 특정 국 가에 대한 종합적인 이미지인 국가 이미지를 형성하 는 하위요소들 중 하나이다(Laroche, Papadopoulos, Heslop, \& Mourali, 2005; Yoo, 2007). 선행연구에 따 르면, 다른 하위 요인들에 비하여 국민이미지가 특히 대상 국가 제품에 대한 신뢰성과 제품 평가에 유의한 영향을 미친다(Shin \& Kim, 2007). 이는 한 국가의 국민의 이미지가 결국 그 국민들이 만든 제품 혹은 연관이 있는 제품에 대한 평가에 영향을 준다는 것을 보여준다(Parameswaran \& Pisharodi, 1994).

$\mathrm{TV}$ 드라마의 등장인물은 일상생활과 같은 스토리 를 전개시키는 드라마 배경, 인물, 스토리가 어우러져 시청자들의 몰입을 높이게 되고, 이는 시청자들이 등 장인물 또는 제품에 대하여 보다 호의적인 태도를 형 성하는데 영향을 주게 된다. 중국 및 일본 소비자들을 대상으로 한 연구에서 Yoo(2007)는 한국 드라마 시청 량 증가에 따라 소비자들이 한국에 대하여 더욱 호의 적으로 느끼고, 한국에 대한 정서적 태도 및 행동의 도가 증가하는 것을 보여주었다. 특히 한국 드라마에 서 보여지는 등장인물 및 한국 사람들의 이미지는 중 국에 비해서 좀 더 빨리 진행된 산업화 및 세계화의 영향으로 세련된 도시화의 모습과 동시에 아시아권 의 전통적인 정서인 순수한 사랑, 예의범절, 공손함, 정직, 배려 등에 가치를 두는 권선징악의 가치를 반 영한다고 보고하였다(Jiang \& Leung, 2012; Kim et 
al., 2009). 점차 개방적이고 서구화되어 가는 중국 사 회에서 현대적이지만 아시아 전통의 정서를 가지고 있는 한국 드라마의 스토리는 시청자로 하여금 등장 인물을 선망하며, 닮고 싶은 느낌이 들게 하기도 한다 (Kim et al., 2009). 뿐만 아니라, 단순노출효과이론 (Zajonc, 1968, 2001)에 따르면, 반복적인 노출은 등 장인물을 통한 한국인들에 대한 친숙도가 증가하게 되고, 이는 전반적인 한국 국민 이미지 형성에 영향 을 미칠 것이다.

$\mathrm{H} 4$ : 한국 TV드라마 시청은 중국 소비자들의 한국 국민 이미지에 정(+)의 영향을 미칠 것이다.

\section{Effects of perceived similarity on people image}

유사-매력 이론(similarity-attraction theory)에 의하 면, 사람은 본인과 닮은 사람에게 매력을 느끼고 좋 아하는 감정을 느끼게 된다(Byrne, 1971). 이는 사람 들은 본인과 유사한 상대방에게 공감을 느끼게 하는 경향이 있기 때문이다(Choi et al., 2012). 유사-매력 이론이 제시된 이후 많은 실증 연구들이 상대방에 대 한 외모 또는 가치관에 대한 지각된 유사함이 높을수 록 그에 대한 호의적인 평가로 이어진다는 것을 보여 주었다(Davis \& Silk, 1972; Evans, 1963). 또한 선행 연구는 직접적인 교류가 없었던 상대방에 대하여 느 끼는 유사함은 외형적 특징을 기준으로 지각되는 경 향이 있으며(Shilinger \& Plummer, 1972; Simpson, Snuggs, Christiansen, \& Simples, 2000; Szybillo \& Jacoby, 1974), 지각된 유사성은 착용자들의 가치관 및 태도에 대한 평가에 있어서도 유사하다고 느끼게 되는 경향이 있음을 보여주었다(Buckley, 1983).

$\mathrm{TV}$ 드라마 요소 중에서 가장 중심이 되는 것은 등 장인물이라 할 수 있다. 시청자는 자신과 유사한 인 물에 대하여 감정적 반응을 보인다(Ryu, 2013). Choi et al.(2012)은 한국 드라마의 인기가 단순히 한류스 타들의 인기에 기인한 것이라기 보다는 드라마에 등 장하는 사회 및 등장인물과의 유사성으로 인한 공감 을 통해 형성될 수 있다는 것을 보여준다. 다시 말해, 사람은 자신의 외형 및 문화와 유사함을 느끼는 상대 방에 대하여 친숙함을 느끼며 호감을 느끼는 것이다 (Kastenholz, 2010; Ryu, 2013). 특히 집단주의 성향 이 강한 중국 소비자들에게 ‘우리와 닮았다'라는 느
낌은 편안함, 매력 등과 같은 호의적인 반응을 일으 킬 것이다. 따라서 중국 소비자들이 TV드라마를 통 해서 접하게 되는 한국 등장인물들과의 지각된 외모 및 가치 유사성이 높을수록 한국인에 대하여 보다 큰 호의적인 이미지를 형성할 것이다.

$\mathrm{H} 5$ : 중국 소비자들의 지각된 외모 유사성은 한국 국민 이미지에 정(+)의 영향을 미칠 것이다.

H6: 중국 소비자들의 지각된 가치 유사성은 한국 국민 이미지에 정(+)의 영향을 미칠 것이다.

\section{Effects of perceived similarity on attitudes toward}

\section{Korean fashion products}

지각된 유사성은 효율적 커뮤니케이션을 통해 설 득력 향상에 영향을 미친다(Janis, Kaye, \& Kirschner, 1965; Rogers, 2005). 외형적 특징뿐 아니라, 성격, 습 관 및 가치관에 있어서의 유사함은 상대방을 보다 더 쉽게 이해할 수 있는 근거를 제공하여 다른 사람들을 비롯한 세상을 이해하는 데 도움을 주게 되기 때문이 다. 구매 환경에서 지각된 유사성은 소비자들과의 커 뮤니케이션 효율을 높여, 소비자 태도 형성에 영향을 미치게 되는 것이다. 구매환경에서 소비자들의 지각 된 유사성의 영향은 많은 연구로 지지되었다. 먼저, 광고연구에서 광고모델과의 지각된 유사성은 광고 효과를 증진시킨다는 것을 보여주었다. 즉, 모델과 유 사하다고 느낄수록 그 광고 또는 제품에 대한 기억이 높고, 이는 그 광고 또는 제품에 대한 호의적인 태도 로 이어진다는 것을 발견하였다(Kwon et al., 2009; McCroskey, et al., 1975; Rogers, 2005; Shlinger \& Plummer, 1972; Simpson et al., 2000; Szybillo \& Jacoby, 1974). 또한 구매환경에서 매장 판매원과의 유사성을 느낄수록 구매의도가 높아짐을 발견하였다 (Brock, 1965; Churchill, Collins, \& Strang, 1975; Evans, 1963; Woodside \& Davenport, 1974).

미디어 연구에서는 시청자들이 미디어에 등장하는 방송인과 유사하다고 느낄수록 그 방송인에 대한 높 은 신뢰와 호의적인 평가를 나타내었으며, 상대방의 특성을 따라 하는 성향도 보였다(Hoffner \& Buchanan, 2005). 이에 대해 Hoffner and Cantor(1991)은 시청자 가 특정 방송인에게서 어느 정도의 유사성을 인지하 게 되면 지각된 유사성이 그 방송인처럼 될 수 있다 
는 일종의 신호로 작용한다고 한다. 즉, 시청자들이 $\mathrm{TV}$ 와 같은 미디어에 나오는 등장인물에 대하여 어 느 정도의 유사함을 느끼게 되면 그 등장인물처럼 될 수 있다는 가능성을 느끼고, 이는 등장인물을 모방하 거나 흥내내고자 하는 바램으로 연결되는 것이다 (Hoffner \& Buchanan, 2005). 의복 및 패션 잡화 등 패션제품은 착용자를 평가하는 여러 단서들 중 가시 성이 높은 단서로서 관찰자의 유사성 지각에 중요한 역할을 하고(Buckley, 1983), 비교적 쉽게 모방할 수 있는 부분으로 관찰자의 주의를 끌게 된다. 이처럼 상대방의 외형적 특성 및 가치관에 대하여 느끼는 유사성은 상대방뿐 아니라, 상대방에 대한 전체적인 이미지 구성에 영향을 주는 패션제품이나 브랜드에 대한 평가에 영향을 줄 것이다. 따라서, 중국 소비자 들이 TV드라마를 시청하면서 등장하는 인물들과 유 사하다고 느낄수록 등장인물과 연관되는 한국 패션 제품에 대하여 호의적인 평가를 할 것이다.

$\mathrm{H7}$ : 중국 소비자들의 지각된 외모 유사성은 한국 패션제품에 대한 태도에 정(+)의 영향을 미칠 것이다.

$\mathrm{H} 8$ : 중국 소비자들의 지각된 가치 유사성은 한국 패션제품에 대한 태도에 정(+)의 영향을 미칠 것이다.

\section{Effects of people image on attitudes toward Korean fashion products}

국가이미지가 해당 국가의 제품 또는 브랜드에 미 치는 영향은 국가이미지의 후광 효과(halo effect) 또 는 종합구조(summary construct) 이론을 이용하여 설 명할 수 있다(Han, 1989; Kleppe, Iversen, \& Stensaker, 2002). 후광효과는 제품 평가에서 국가이미지가 제품 의 다른 속성들과 함께 하나의 제품 속성으로 작용하 여 제품 태도 형성에 영향을 주는 과정을 설명한다 (Huber \& McCann, 1982). 종합구조 이론은 국가이미 지 또는 브랜드 이미지가 해당 국가의 제품에 대한 종 합적인 판단 기준이 되어 제품 태도 형성에 직접적인 영향을 미치게 된다고 설명한다(Han, 1989). 후광효 과는 제품에 대한 정보가 부족하여 친숙하지 않은 제 품 평가의 경우 주요하게 작용한다(Han, 1989). 한국 드라마 노출로 인해 어느 정도의 친숙도가 있는 중국 소비자들에게 한국에 대한 국가이미지가 한국 패션 제품에 대한 태도에 미치는 영향은 후광효과보다는 종
합구조 이론을 바탕으로 설명할 수 있다. 이를 바탕 으로, 한국에 대한 국가이미지가 한국 패션제품에 대 한 태도에 직접적인 영향을 미칠 것이라고 예상할 수 있다.

국민이미지는 국가이미지를 형성하는 주요 요인 중 하나로서, 해당국가의 제품에 대한 평가에 특히 중요한 역할을 한다(Ha \& Hwang, 2014; Shin \& Kim, 2007). Shin and $\operatorname{Kim}(2007)$ 에서는 국가의 경제적 이미지 및 관계적 이미지는 제품에 대한 인식에 유의한 영향을 미치지 않은 반면, 국민이미지는 한국 제품에 대한 태 도에 유의한 영향을 미치는 것으로 나타났다. 구체적 으로 국민이미지는 한국 제품에 대한 신뢰를 높이고, 친숙도를 향상시키는 결과를 보여주었다. 즉, 한국 사 람의 공손함, 정직성, 교육수준, 교양, 배려심 등으로 구성된 한국 국민이미지가 결국 한국 사람이 만들거 나, 한국 사람과 연관된 제품에 대한 평가에 영향을 미치는 것이다. 한국 패션제품에 대한 선행연구에서 는, 중국 소비자들이 한국 국민들의 패션감각이 뛰어 나다고 느낄수록 한국 패션제품에 대한 호의적인 이 미지를 보였으며, 한국 국민들의 교육수준이 높고 믿 을만하다고 느낄수록 한국 제품이 보다 고급스럽고 명성이 높다고 평가하였다(Ha \& Hwang, 2014). 결론 적으로, 한국 국민들에 대한 이미지가 높을수록 한국 패션제품에 대한 평가가 높아지는 것을 보여주었다. 선행연구를 바탕으로 한국 국민이미지는 한국 패션 제품에 대한 태도에 직접적인 영향을 미칠 것이라는 가설을 제시할 수 있다.

H9: 한국 국민 이미지는 한국 패션제품에 대한 태 도에 정 $(+)$ 의 영향을 미칠 것이다.

\section{Methods}

\section{A proposed model}

본 연구는 중국 소비자들의 한국 드라마 시청으로 인해 지각되는 한국인과의 유사성과 국민이미지 및 이로 인한 한국 패션제품에의 태도를 설명하고자 하 였다. 관련 이론과 선행연구를 통해 한국 드라마 시 청 정도, 지각된 외모 유사성, 지각된 가치 유사성, 국 민이미지 및 한국 패션제품에의 태도 간의 영향 관계 를 분석하기 위해 가설을 제시하였으며, 이를 바탕으 
로〈Fig. 1〉과 같은 연구모델을 제시하였다.

\section{Measure}

본 연구모형의 모든 변수는 선행연구를 바탕으로 측정되었다. 한국 TV드라마 시청량은 Jun and Zhang (2012)의 한국 TV드라마 노출에 대한 측정문항과 동 일하게 일주일동안 한국 드라마 평균 시청 횟수를 묻 는 문항으로 측정하였다. 지각된 외모 유사성 및 가치 유사성은 McCroskey et al.(1975)의 지각된 동질성(perceived homophily) 개념의 측정 문항 중 외모 유사성 (appearance homophily) 및 가치 유사성(value homophily) 개념의 측정문항을 7점 의미분별(Semantic Differential) 척도를 사용하여 측정하였다. 국민이미지(Shin \& Kim, 2007) 및 패션제품에 대한 태도(Han, 1989; Oyunkhuu \& Park, 2015)는 선행연구를 바탕으로 구성된 문항에 대한 동의 정도를 묻는 7점 Likert 척도로 측정하였다.

\section{Data collection and sample characteristics}

본 연구에서 제시한 연구모형 및 가설을 실증분석 하기 위하여 소비자 설문조사를 실시하였다. 구체적 으로 중국 소비자 패널을 보유한 중국 시장조사 회사 를 이용하여 편의표본추출방법을 이용하여 온라인 설 문을 실시하였다. 연구대상은 한국 드라마 및 패션제 품을 본 적이 있는 중국 거주 20대 소비자로 제한하였 다. 설문지는 먼저 한글로 작성된 뒤 한국어 및 중국 어를 구사하는 두 명의 번역가에 의하여 역번역의 과 정을 거쳐 중국어 설문지를 개발하였다. 중국어 설문 지는 중국 시장조사/설문 사이트를 이용하여 온라인
으로 진행되었으며, 총 317 부의 완료된 설문지가 수 거되었다.

응답자의 인구통계학적 특성을 알아보기 위하여 SPSS21을 이용하여 빈도분석을 실시하였다. 응답자 의 성별은 남성 156 명(49.2\%)과 여성 161 명(50.8\%)으 로 구성되어 성별비율은 비슷하였으며, 평균 연령은 25 세(최소값 $=21$, 최대값 $=30$ )이었다. 학력수준은 4 년 제 대학 재학중 또는 졸업(74.1\%)이 가장 높았으며, 그 다음으로 전문대 재학 또는 졸업(14.2\%), 석사과정 대학중 또는 졸업(8.2\%), 고등학교 졸업 이하 $(3.2 \%)$, 박사재학중 또는 졸업 $(0.3 \%)$ 의 순이었다. 직업은 문서 직(회사원, 공무원, 은행 등)이 $28.7 \%$ 로 가장 많았으 며, 전문직(의사, 법조계, 연구원, 교수, 교사, 작가 등)(23.3\%), 학생(16.1\%), 경영관리직(고급공무원, 기 업관리자, 기업 간부 등)( $15.8 \%)$, 판매직( $4.7 \%)$, 생산 직(4.4\%), 자영업(3.5\%), 기타 직업 $(2.5 \%)$, 주부 $(0.9 \%)$ 의 순서로 나타났다. 월평균 소득은 2,500 위안 이상 5,000 위안 미만라고 답한 응답자 비율이 $33.4 \%$ 로 가 장 높았으며, 그 다음으로 5,000 위안 이상 10,000 위안 미만(30.0\%), 2,500 위안 미만(20.5\%), 10,000 위안 이 상 15,000 위안 미만(10.4\%), 15,000 위안 이상 20,000 위안 미만(4.1\%), 30,000 위안 이상(0.9\%), 20,000 위안 이상 25,000 위안 미만 $(0.6 \%)$ 의 순으로 나타났다.

\section{N. Data Analyses and Results}

연구모형검증 및 가설검증을 위하여 $\operatorname{AMOS} 21$ 을 사 용하여 확인적 요인분석(Confirmatory Factor Analysis:

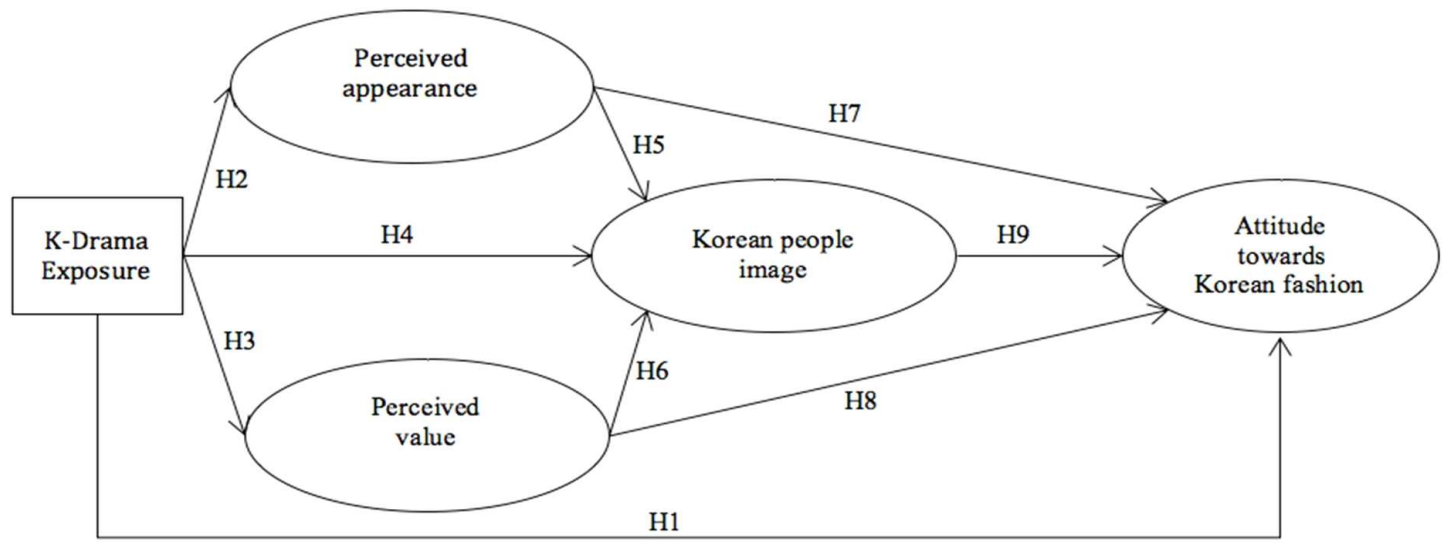

$<$ Fig. 1> A proposed model 
CFA) 및 구조방정식모델분석(Structural Equation Modeling Analysis: SEM)을 실시하였다.

\section{Assessment of measurement model}

본 연구는 가설검증에 앞서 다수문항으로 측정된 지각된 외모 유사성, 지각된 가치 유사성, 국민이미지, 한국 패션제품에 대한 태도의 구성개념에 대한 신뢰 도(Composite Reliability: $\mathrm{CR}$ ) 및 타당성을 분석하기 위하여 $\mathrm{CFA}$ 를 실시하였다. 교차적재를 보여 문제가 되었던 두 개의 문항을 삭제한 후 수정된 측정모형은 적합하였으며 $\left(\chi^{2}=132.44, d f=70, p<.001, \mathrm{CMIN} / d f=1.89\right.$, $\mathrm{TLI}=.96, \mathrm{CFI}=.97, \mathrm{RMSEA}=.06)$, 구성항목의 성격은 〈Table 1)과 같다. 즉, 모든 개념의 평균분산추출값 (Average Variance Extracted: AVE)은 .51 이상이고, 신뢰도는 .76 이상이었으며, 각 구성개념에 대한 요인 부하량은 통계적으로 유의하며, .65 이상으로 나타나 수렴타당성을 보여주었다. 또한〈Table 2〉에서 보듯이,
각 개념의 $\mathrm{AVE}$ 값과 각 구성개념간의 상관관계 제곱 값의 비교를 통해 판별타당성을 확인하였다(Fornell \& Larcker, 1981).

\section{Hypotheses testing}

본 연구에서는 가설검증을 위해 $\mathrm{SEM}$ 을 실시한 결 과, 모델접합도는 수용 가능한 수준으로 나타났다 $\left(\chi^{2}\right.$ $=208.75, d f=81, p<.001, \mathrm{CMIN} / d f=2.58$, TLI $=.92, \mathrm{CFI}=$ .94, RMSEA=.07). 연구모형에 대한 검증 결과는 〈Fig. 2)에서 볼 수 있다.

$\mathrm{H} 1, \mathrm{H} 2, \mathrm{H} 3$ 및 $\mathrm{H} 4$ 는 중국 소비자들의 한국 드라마 시청 정도가 한국 패션제품에 대한 태도( $\mathrm{H} 1)$, 드라마 에 등장한 한국인들과의 지각된 외모 유사성 $(\mathrm{H} 2)$, 가 치 유사성(H3) 및 한국인에 대한 국민이미지(H4)에 미 치는 영향을 알아보는 것이었다. 분석 결과, 중국 소 비자들의 한국 드라마 시청량은 한국 패션제품에 대한 태도 $(\beta=.16, t=5.54, p<.001)$, 지각된 외모 유사성 $(\beta=$

$<$ Table 1 $>$ The result of confirmatory factor analysis

\begin{tabular}{|c|c|c|c|c|c|c|}
\hline Construct & Item & $\begin{array}{l}\text { Std. factor } \\
\text { loading }\end{array}$ & $t$ & Cronbach's $\alpha$ & AVE & $\mathrm{CR}$ \\
\hline \multirow{3}{*}{$\begin{array}{l}\text { Perceived } \\
\text { appearance } \\
\text { similarity }\end{array}$} & $\begin{array}{l}\text { looks different from me / looks similar to } \\
\text { me }\end{array}$ & .74 & $13.27^{* * *}$ & \multirow{3}{*}{.76} & \multirow{3}{*}{.51} & \multirow{3}{*}{.76} \\
\hline & $\begin{array}{l}\text { have the different size than I am / have } \\
\text { the same size I am. }\end{array}$ & .65 & $11.47^{* * *}$ & & & \\
\hline & $\begin{array}{l}\text { have appearance unlike mine / have } \\
\text { appearance like me. }\end{array}$ & .75 & $13.45^{* * *}$ & & & \\
\hline \multirow{3}{*}{$\begin{array}{l}\text { Perceived } \\
\text { value } \\
\text { similarity }\end{array}$} & $\begin{array}{l}\text { sexual attitudes unlike mine / sexual } \\
\text { attitudes like mine }\end{array}$ & .71 & $13.02^{* * *}$ & \multirow{3}{*}{.76} & \multirow{3}{*}{.52} & \multirow{3}{*}{.77} \\
\hline & doesn't share my values / shares my value & .77 & $14.38^{* * *}$ & & & \\
\hline & $\begin{array}{l}\text { doesn't treat people like I do / treats } \\
\text { people like I do }\end{array}$ & .68 & $12.20^{* * *}$ & & & \\
\hline \multirow{5}{*}{$\begin{array}{l}\text { Korean people } \\
\text { image }\end{array}$} & Korean people are well-mannered. & .76 & $15.28^{* * *}$ & \multirow{5}{*}{.90} & \multirow{5}{*}{.60} & \multirow{5}{*}{.88} \\
\hline & Korean people are well-educated. & .66 & $12.84^{* * *}$ & & & \\
\hline & Korean people are honest. & .84 & $18.04^{* * *}$ & & & \\
\hline & Korean people are sophisticated. & .84 & $17.82^{* * *}$ & & & \\
\hline & Korean people are considerate. & .76 & $15.08^{* * *}$ & & & \\
\hline \multirow{3}{*}{$\begin{array}{l}\text { Attitude toward } \\
\text { Korean fashion } \\
\text { products }\end{array}$} & I like Korean fashion products. & .86 & $17.78^{* * *}$ & \multirow{3}{*}{.85} & \multirow{3}{*}{.68} & \multirow{3}{*}{.86} \\
\hline & $\begin{array}{l}\text { I have great interest in Korean fashion } \\
\text { products. }\end{array}$ & .89 & $19.04^{* * *}$ & & & \\
\hline & $\begin{array}{l}\text { I feel sense of closeness toward Korean } \\
\text { fashion products }\end{array}$ & .71 & $13.90^{* * *}$ & & & \\
\hline
\end{tabular}

${ }^{* * *} p<.001$ 
<Table 2> The squared correlations and AVE of variables

\begin{tabular}{|c|c|c|c|c|}
\hline & 1 & 2 & 3 & 4 \\
\hline Perceived appearance similarity (1) & $.51^{\mathrm{a}}$ & & & \\
\hline Perceived value similarity (2) & $.36^{\mathrm{b}}$ & .52 & & \\
\hline Korean people image (3) & .22 & .36 & .60 & \\
\hline Attitude toward Korean fashion products (4) & .14 & .12 & .32 & 68 \\
\hline
\end{tabular}

a: Average Variance Extracted (AVE) for constructs are displayed on the diagonal.

b: Numbers below the diagonal are squared correlation estimates of two variables.

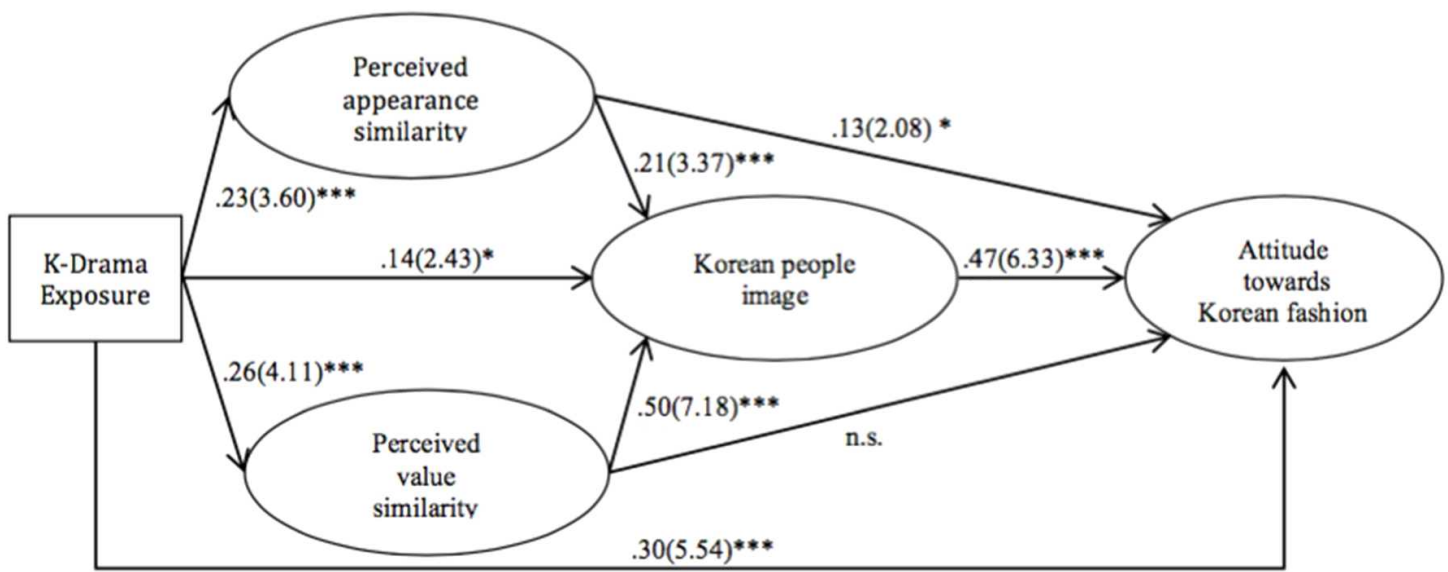

<Fig. 2> Resulted model. Numbers are standardized regression weights and Critical Ration (CRs) in parentheses. ${ }^{*} p<.05, \quad{ }^{* * *} p<.001$. n.s. $=$ not significant

$.11, t=3.60, p<.001)$, 지각된 가치 유사성 $(\beta=.12, t=$ $4.11, p<.001)$ 및 한국 국민에 대한 이미지 $(\beta=.06, t=$ $2.43, p<.05)$ 에 모두 유의한 영향을 미치는 것을 보이 며, 한국 드라마 시청의 영향과 관련된 모든 가설(H1, $\mathrm{H} 2, \mathrm{H} 3, \mathrm{H} 4)$ 을 지지하였다. 즉, 한국 드라마 시청량 이 증가할수록 중국 소비자들의 한국 패션제품에 대 하여 보다 호의적인 태도를 보인다는 것을 나타낸다. 또한 한국 드라마 시청량이 증가할수록 중국 소비자 들은 한국 드라마에 등장하는 한국인들과 외모뿐만 아니라, 가치에 있어서도 유사하다고 느끼는 것을 알 수 있다. 더욱이 한국 드라마 시청의 증가는 일반적 인 한국 국민에 대한 호의적인 이미지 형성에 직접적 인 영향을 미치는 것을 보여준다. Yoo(2007)의 연구에 서 한국 드라마 시청량은 중국인들의 한국에 대한 연 상 및 이미지 형성에 긍정적인 영향을 준다는 것을 보여주었는데, 본 연구는 한국 드라마가 특히 드라마 등장인물뿐 아니라, 한국인에 대한 연상 및 이미지 형
성에 영향을 미친다는 것을 제안함으로 한국에 대한 이미지 중 사람에 대한 이미지의 역할을 구체적으로 보여주었다. 이와 같은 결과는 사람은 반복적으로 노 출된 대상에 대해서 친숙함을 느끼고, 그 대상을 좋아 하게 된다는 단순노출효과 이론(Zajonc, 1968, 2001) 을 지지하며, 이 이론이 TV 매체를 통해 접하는 타문 화권의 대상에 미치는 영향에 대해서도 설명할 수 있 음을 보여주었다.

$\mathrm{H} 5$ 와 H6는 중국 소비자들이 드라마에 등장하는 한국인들과 외모 및 가치에 있어서 유사하다고 느끼 는 정도가 한국인에 대한 이미지에 미치는 영향을 평 가하는 것이었다. 검증결과, 중국 소비자들의 지각된 외모 유사성 $(\beta=.20, t=3.37, p<.001)$ 과 지각된 가치 유 사성 $(\beta=.51, t=7.18, p<.001)$ 은 모두 한국 국민에 대 한 이미지에 유의한 영향을 미치는 것으로 나타났다. 이러한 결과는 한국 $\mathrm{TV}$ 드라마에 등장하는 인물들에 대하여 지각된 유사성이 한국 국민에 대한 이미지 향 
상에 긍정적인 영향을 준다는 것을 보여준다. 구체적 으로 인물의 외형뿐 아니라, 가치에 대한 유사성 지 각이 모두 유의한 영향을 미치는 것을 보여주었다. 이는 특정 국가 국민의 매너, 교육수준, 정직, 배려 등 을 토대로 총체적으로 평가하는 이미지인 국민 이미지 형성에 다소 관계가 멀어보이는 드라마 등장인물의 외형적 유사성 및 가치관 유사성이 함께 영향을 미친 다는 것을 보여준다. 이와 같은 결과는 고전 이론 중 하나인 유사-매력 이론(Byrne, 1971)을 지지하며, 이 이론이 TV 매체를 통한 국가간 커뮤니케이션 현상에 도 적용됨을 보여준다.

중국 소비자들이 지각하는 드라마 등장인물들과의 외모 및 가치 유사성 정도가 한국 패션제품에 대한 태도에 미치는 영향에 관한 $\mathrm{H} 7$ 과 $\mathrm{H} 8$ 에 대한 검증 결 과, 지각된 외모 유사성은 한국 패션제품에 대한 태 도에 유의한 영향 $(\beta=.14, t=2.08, p<.05)$ 을 준다는 것 을 발견하였으나, 지각된 가치유사성이 미치는 유의 한 영향은 발견하지 못하였다. 따라서 $\mathrm{H} 7$ 은 채택되었 으나, H8은 기각되었다. 유의한 결과는 나타낸 외모 유사성의 영향은 중국 소비자들이 한국 드라마 등장 인물과의 외형적으로 유사하다고 느낄수록 한국 패 션제품에 대하여 보다 호의적인 태도를 가지고 있다 는 것을 보여준다. 소비자의 패션제품에 대한 평가에 는 착용자의 신체적 특징, 피부색, 헤어색 등 외형적 요인이 중요하고, 패션제품이 착용자와 얼마나 어울 리는 지가 중요한 요인이 된다. 따라서, 중국 소비자 들이 한국 드라마를 시청하면서 등장인물들과 중국 인들이 외형적으로 유사하다고 느끼는 정도는 한국 패션제품에 대한 태도 형성에 강한 영향을 줄 수 있 다는 것을 보여준다. 하지만, 지각된 가치 유사성은 유의한 영향을 미치지 못했는데, 이와 같은 결과는 등장인물에 대한 유사성 지각시 인물의 다양한 속성 중 외형적인 특징이 가치와 같은 개인 성향보다 등장 인물과 연관되는 제품에 대한 태도 형성에 더 강한 영향을 준다는 것을 보여준다. 연구 결과에 대한 가 능한 설명으로는, 패션제품의 특성상 패션제품에 대 한 평가는 착용자의 개인적 가치 성향보다는 인물 외 형적인 요소와 제품이 어울리는 지가 더욱 중요한 요 소일 수 있을 것이다. 하지만, 본 연구에서는 패션 외 다른 제품군에 대한 태도는 측정하지 않았으므로 이 같은 결과가 패션제품군의 특성에 기인한다고 단정
하기는 어렵다. 따라서, 이에 대해서는 후속 연구가 필요할 것이다.

마지막으로 중국 소비자들이 지각하는 한국 국민 에 대한 이미지는 한국 패션제품에 대한 태도에 유의 한 영향 $(\mathrm{b}=.54, t=6.33, p<.001)$ 을 미치는 것으로 나타 나 $\mathrm{H} 9$ 는 지지되었다. 즉, 중국 소비자들이 한국인에 대해서 호의적으로 평가할수록 한국 패션제품을 보 다 긍정적으로 평가하는 것으로 나타났다. 이 결과는 종합구조이론(Huber \& McCann, 1982) 및 선행연구 들(Jun \& Zhang, 2012; Shin \& Kim, 2007)에서 국민 이미지가 제품 평가에 미치는 영향을 보여준 것과 그 방향이 일치하며, 본 연구에서는 중국의 이전 세대와 달리 개방화 및 세계화의 영향을 많이 받고 자란 20 대 소비자들과 한국 패션제품을 대상으로 관계성을 보여주었다. 빠른 산업화와 급변하는 사회적 분위기 속에서 자란 20 대 중국 소비자들에게도 한 국가의 패 션제품에 대한 태도 형성에는 그 나라 국민에 대한 이미지가 중요한 역할을 한다는 것을 보여주었다. 모 든 가설에 대한 검증 결과 요약은 〈Table 3〉에서 제 시하였다.

\section{Conclusion and Discussion}

본 연구는 20 대 중국 소비자들의 한국 드라마 시청 이 한국 패션제품에 대한 태도에 미치는 영향에 대해 서 알아보고자 하였으며, 중국 소비자들이 드라마를 통한 등장인물들과 형성하는 커뮤니케이션의 관점에 서 이 현상을 설명하고자 하였다. 본 연구에서 제시하 는 연구모형은 크게 중국 소비자들의 드라마 시청량 에 따른 영향과 중국 소비자들이 등장인물들에 대하 여 느끼는 유사성이 미치는 영향으로 구성되었다. 드 라마 시청량에 따른 영향은 단순노출효과 이론을 이 용하여 설명하고자 하였으며, 중국 소비자들이 지각 하는 유사성에 따른 영향은 유사-매력이론을 이용하 여 설명하고자 하였다.

연구결과를 요약하면 다음과 같다. 먼저, 한국 드 라마 시청량이 늘어날수록 지각된 유사성, 한국 국민 이미지, 한국 패션제품에 대한 호의적인 평가를 보임 을 알 수 있었다. 또한 중국 소비자들이 한국 드라마 의 등장인물들과 외모 및 가치관이 비슷하다고 느낄 수록 일반 한국 국민에 대하여 호의적인 평가를 하였 
$<$ Table 3> Results of structural equation model

\begin{tabular}{|c|c|c|c|}
\hline Structural paths & Standardized coefficient & S.E. & $t$ \\
\hline K-Drama exposure $\rightarrow$ Attitude & .30 & .03 & $5.54^{* * *}$ \\
\hline K-Drama exposure $\rightarrow$ Appearance similarity & .23 & .03 & $3.60^{* * *}$ \\
\hline K-Drama exposure $\rightarrow$ Value similarity & .26 & .03 & $4.11^{* * *}$ \\
\hline K-Drama exposure $\rightarrow$ People image & .14 & .03 & $2.43^{*}$ \\
\hline Appearance similarity $\rightarrow$ People image & .21 & .06 & $3.37^{* * *}$ \\
\hline Value similarity $\rightarrow$ People image & .50 & .07 & $7.18^{* * *}$ \\
\hline Appearance similarity $\rightarrow$ Attitude & .13 & .07 & $2.08^{*}$ \\
\hline Value similarity $\rightarrow$ Attitude & -.08 & .09 & -1.03 \\
\hline People image $\rightarrow$ Attitude & .47 & .09 & $6.33^{* * *}$ \\
\hline
\end{tabular}

${ }^{*} p<.05,{ }^{* * *} p<.001$

다. 하지만, 한국 패션제품에 대한 태도에는 지각된 외모 유사성만 유의한 영향을 나타냈으며, 가치 유사 성의 영향은 유의하지 않았다. 마지막으로, 한국 국민 에 대한 이미지는 한국 패션제품에 직접적인 영향을 미침을 알 수 있었다. 이상의 결과를 토대로 다음과 같은 결론 및 시사점을 제시할 수 있다.

첫째, 한국 드라마 시청량이 지각된 유사성, 한국 국민 이미지 및 한국 패션제품에 미치는 직접적인 영 향은 단순노출효과 이론을 지지함을 보여준다. 즉, 드 라마 노출량이 증가하면서 등장인물에 대한 지각뿐 아니라, 일반적인 한국인에 대한 이미지 및 패션제품 에 대한 호의적인 태도 역시 증가함을 실증 분석을 통 해 확인하였으며, 이 결과는 한류 문화 콘텐츠의 다양 한 파급효과를 나타낸 선행연구들과 그 맥을 함께 하 였다. 현재 많은 한국 기업들이 제품 이미지 제고 및 이를 통한 경제적 효과를 기대하며, 한국 스타를 마케 팅 수단으로 이용하고 있지만, 본 연구는 스토리를 배 경으로 등장인물들의 특성 및 전체적인 라이프스타일 을 함께 보여주는 드라마와 같은 문화 콘텐츠 역시 제 품 태도 향상을 통해 경제적 효과를 기대할 수 있음을 보여준다.

둘째, 본 연구는 선행연구에서 부족했던 부분인 한국 드라마를 비롯한 한류가 제품 평가에 미치는 영 향 과정에서 소비자들의 내적 반응에 대한 부연설명 을 추가하고자 하였다. 이처럼 특정 환경 또는 제품 에 대한 소비자 행동에서 그 기저를 이루는 소비자들 의 내적 반응에 대한 이해는 단순 소비자 행동의 동
기를 밝히는 연구보다 더 중요할 수 있다(Oberecker \& Diamantorpoulous, 2011). 이에 본 연구는 드라마 시청에서 중국 소비자들이 지각하는 외모 유사성 및 가치 유사성의 역할을 제시하고, 지각된 유사성의 정 도가 일반 한국인에 대한 이미지 및 한국 패션제품에 대한 태도에 직접적인 영향을 미친다는 것을 보여줌 으로써, 유사-매력 이론을 지지하였다. 유사성 지각에 영향을 주는 다양한 요소들(McCroskey et al., 1975) 중에서 본 연구에서는 외형적 유사성뿐 아니라, 가치 유사성이 국민 이미지에 강한 영향을 미치는 것을 보 여주었다. 중국 소비자들에게 TV드라마의 등장인물 들이 나와 비슷한 생각을 하고, 윤리적 의식 및 타인 을 대하는 태도 등이 유사하다는 느낄수록 드라마 제 작국가의 일반 국민들에 대하여 보다 호의적인 이미 지 형성한다는 것을 알 수 있다. 이는 중국인들에게 ‘우리와 가깝다'라는 느낌은 정서적인 호감과 특히 강하게 연결된다는 문화적 근접성에 대한 선행연구 와 일치한다(Ryu, 2013). 흥미로운 점은 급변하는 사 회속에서 이전 세대에 비교해서 개인적이고 개방적인 라이프스타일을 추구하는 현재 20대 소비자들에게도 인물에 대한 이미지 평가에서 상대방의 가치관이 중 요하다는 점이다. 따라서, 중국 소비자들을 염두에 두 는 패션 기업은 타겟 소비자층의 가치관에 대한 이해 가 필요하고, 마케팅 커뮤니케이션에서 이를 반영해 야 할 것이다.

셋째, 중국 소비자들은 드라마 등장인물들에 대한 지각된 외모 유사성이 높을수록 한국 패션제품에 대 
한 긍정적인 태도를 보여주었다. 이는 지각된 외모 유 사성이 중국 소비자들에게 휴리스틱 단서(heuristic cue)로 이용될 수 있다는 것을 보여준다. 소비자들은 특정제품에 대하여 태도를 결정할 때 제품의 품질, 브 랜드, 가격, 광고, 점포 등 많은 요소를 분석하여 태도 를 결정하기 보다는 기분과 같은 특정한 휴리스틱 단 서가 크게 작용하여 소비자 태도 형성에 직접적으로 작용하기 때문이다(Chaiken \& Maheswaran, 1994). 이와 같은 현상은 분석적 사고 성향을 가진 서구권 문 화의 소비자들에 비하여 전체론적(holistic) 사고 성향 을 가진 동양권 문화의 중국 소비자에게서 더 많이 발 견될 수 있다(Monga \& John, 2007). 특히 이 결과는 패션제품은 착용자의 외형적 요인과 제품과의 조화 가 중요하기에, 매체를 통해 노출되는 제품들에 대한 평가에서 제품을 입은 착용자인 등장인물들과 자신 을 비교하여 어느 정도의 유사성이 발견될 때 보다 호 의적인 제품에 대한 평가로 이어지는 것으로 이해할 수 있다.

넷째, 중국 소비자들의 한국 패션제품에 대한 태도 는 국민이미지에 의해 강한 영향을 받는다는 결과는 한국 국민에 대한 이미지가 경제적 가치와 관련되며, 한국 경제에서 중요한 요소라는 것을 보여준다. 즉, 본 연구의 결과는 국민에 대한 이미지는 제품 태도 형성에 중요한 선행요인이므로 마케팅 커뮤니케이션 에서 활용할 수 있는 중요한 요소임을 강조한다.

마지막으로, 본 연구에서 지각된 외모 유사성은 중 국 소비자들의 한국 패션제품에 대한 태도에 미치는 영향을 보여주었지만, 지각된 가치는 유의한 관계를 보여주지 못하였다. 선행연구에서는 광고 모델, 판매 원, 또는 방송인 등과의 지각된 유사성이 관련 제품 평가에 영향을 준다고 하였으나, 본 연구는 지각된 외 형 유사성만이 유의한 영향을 보여주었다. 이와 같은 상이한 결과를 바탕으로 유사성에 대한 다양한 하위 요인들 중 상황 또는 제품에 따라 선택적으로 영향을 미칠 가능성을 고려해볼 수 있다. 즉, 패션제품군에서 는 착용자의 가치관보다는 외형적 요소가 더 중요할 수 있을 것이다. 패션제품에 대한 태도 결정에는 착 용자의 외모, 피부 및 헤어 색, 체형 특징이 패션제품 의 스타일 및 색상과 어울리는 지가 중요하다. 본 연 구는 패션 외 다른 제품군에 대한 소비자 태도를 측정 하지 않았으므로, 유사성의 개별 하위요인들과의 관
계를 알 수 없다. 향후 다양한 제품군에서의 상대적 영향력 차이를 비교해보는 연구가 필요할 것이다.

이상의 결과를 토대로 중국 소비자들은 드라마를 통해서 등장인물과 유사성의 정도를 지각하고, 한국 국민에 대한 이해를 하며, 이를 통해 패션제품과 같 은 한국제품에 대한 태도를 형성한다는 것을 알 수 있다. 즉, 중국 소비자들은 TV 매체를 통해 등장인물 들과 커뮤니케이션을 하고, 이를 토대로 한국인 및 한국 제품에 대해서 평가를 한다고 할 수 있다. 한류 의 경제적 효과를 지속적으로 유지하기 위해서는 유 사성뿐 아니라, 효과적인 커뮤니케이션을 통해 중국 소비자들의 드라마 시청에 대한 다양한 심리적 반응 에 대한 이해가 선행되어야 것이다.

본 연구는 다음과 같은 한계점을 지니고 있으므로 본 연구 결과를 해석할 때 고려해야 할 것이다. 한계 점 및 향후 연구를 위한 제언은 다음과 같다. 첫째, 본 연구는 편의표본추출법을 사용하였고, 연구 대상 을 20 대만을 한정하였으므로, 전체 소비자 연령으로 일반화하는 데는 무리가 있을 수 있다. 특히 급변하 는 중국 사회에서 소비자들은 다양한 연령에 따라 사 회문화적 배경, 드라마 선호도, 문화적 가치, 과거 패 션 브랜드 노출 정도 등 주요 영향변수에서 상이한 반응을 보일 수 있을 것이다. 따라서, 향후 연구에서 는 표본 연령대를 확대하여 보다 정교한 연구를 할 필요가 있을 것이다.

둘째, 본 연구는 드라마 시청 정도를 측정하기 위 하여 단순히 한국 드라마 시청량을 기준으로 하였다. 하지만, 동일 편수를 시청하였다고 하더라도 드라마 의 질, 전문성, 장르, 시대배경, 드라마 시청 경로 등 드라마 시청과 관련된 변수에서 상이한 반응이 나타 날 수 있을 것이다. 따라서, 이와 같은 드라마 시청과 관련된 변수의 차이를 통제하거나, 변수들의 특정을 고려한 연구가 필요할 것이다.

셋째, 본 연구에서는 특정 드라마에 대한 소비자 반응을 조사한 것은 아니므로 개인 소비자가 시청하 였던 다양한 드라마에서 나타내는 소비자들의 가치 체계는 상이할 수 있으나, 본 연구에서는 이를 고려 하지 않았다. 더욱이 현재 20 대 소비자들의 가치체계 는 무엇인지를 구체적으로 알 수가 없다. 빠른 산업 화에 따라 사회문화적으로 급변하는 사회에서 소비 자들의 가치관은 연령별로 상이하게 나타날 수 있으 
며, 사회분위기의 변화에 따라 변할 수도 있을 것이 다. 따라서 패션 기업은 타겟 소비자들의 가치체계에 대한 지속적인 연구가 필요할 것이다. 또한 향후 세 대별 추구하는 가치 체계와 한국 드라마 시청 후 소 비자 반응과의 관계를 연구하는 것이 필요할 것이다.

마지막으로, 거대 중국에서 지역별로 산업 발달 및 역사적 배경, 외국문화의 노출정도가 상이하다. 이에 따라 소비자들의 가치관 및 외형적 특징도 상이할 수 있다. 하지만, 본 연구에서는 지역별 차이를 고려하지 않았으므로, 향후 지역별 차이를 고려한다면 보다 체 계적인 연구가 가능할 것이다.

\section{References}

Bagozzi, R. P. (1981). Attitudes, intentions, and behavior: A test of some key hypotheses. Journal of Personality and Social Psychology, 41(4), 607-627. doi:10.1037/0022-3514.41.4.607

Brock, T. C. (1965). Communication-recipient similarity and decision change. Journal of Personality and Social Psychology, 1(6), 650-654. doi:10.1037/h0 022081

Buckley, H. M. (1983). Attraction toward a stranger as a linear function of similarity in dress. Family and Consumer Sciences Research Journal, 12(1), 25-34. doi:10.1177/1077727X8301200103

Busselle, R. W., \& Shrum, L. J. (2003). Media exposure and exemplar accessibility. Media Psychology, 5(3), 255-282. doi:10.1207/S1532785XMEP0503 02

Byrne, D. E. (1971). The attraction paradigm. New York: Academic Press.

Castro, M. (2015, Aug 10). Luxury brands in China lose market share as consumers become more price-sensitive. YIBADA, Retrieved December 2, 2016, from http://en.yibada.com/articles/52600/2015 0810/luxury-brands-china-lose-market-share-cons umers-become-more-price.htm

Chaiken, S., \& Maheswaran, D. (1994). Heuristic processing can bias systematic processing: Effects of source credibility, argument ambiguity, and task importance on attitude judgment. Journal of Person- ality and Social Psychology, 66(3), 460-473. doi: $10.1037 / / 0022-3514.66 .3 .460$

Choi, N. H., Lim, A. Y., \& Meng, N. (2012). Chinese consumers' attachment to Korean soap opera and sympathy-inducing factors. Journal of Business Research, 27(4), 107-127.

Churchill, G. A., Collins, R. H., \& Strang, W. A. (1975). Should retail salespersons be similar to their customers?. Journal of Retailing, 51(3), 29-42.

Davis, H. L., \& Silk, A. J. (1972). Interaction and influence processes in personal selling. Sloan Management Review, 13(2), 56-76.

Evans, F. B. (1963). Selling as a dyadic relationship: A new approach. The American Behavioral Scientist, 6(9), 76-79.

Fornell, C., \& Larcker, D. F. (1981). Evaluating structural equation models with unobservable variables and measurement error. Journal of Marketing Research, 18(1), 39-50. doi:10.2307/3151312

Gilly, M. C., Graham, J. L., Wolfinbarger, M. F., \& Yale, L. J. (1998). A dyadic study of interpersonal information search. Journal of the Academy of Marketing Science, 26(2), 83-100. doi:10.1177/00 92070398262001

Ha, J., \& Hwang, J.-S. (2014). The impact of Korean country image on brand identity, brand attitude and purchase intention: A case for Chinese consumers. Journal of the Korean Society of Clothing and Textiles, 38(2), 251-265. doi:10.5850/JKSCT.2014. 38.2 .251

Han, C. M. (1989). Country image: Halo or summary construct?. Journal of Marketing Research, 26(2), 222-229. doi:10.2307/3172608

He, S., Ling, G., \& Li, J. (2013, May). Winning China's apparel market. A.T. Kearney, Retrieved December 2, 2016, from http:/www.atkearney.com/ fr/paper/-/asset_publisher/dVxv4Hz2h8bS/content/ winning-chinas-apparel-market/10192

Hekkert, P., Thurgood, C., \& Whitfield, T. W. A. (2013). The mere exposure effect for consumer products as a consequence of existing familiarity 
and controlled exposure. Acta psychologica, 144(2), 411-417. doi:10.1016/j.actpsy.2013.07.015

Hoffner, C., \& Buchanan, M. (2005). Young adults' wishful identification with television characters: The role of perceived similarity and character attributes. Media psychology, 7(4), 325-351. doi:10.1207/ S1532785XMEP0704_2

Hoffner, C., \& Cantor, J. (1991). Perceiving and responding to mass media characters. In J. Bryant \& D. Zillmann (Eds.), Responding to the screen: Reception and reaction processes (pp.63-101). Mahwah: Lawrence Erlbaum.

Huber, J., \& McCann, J. (1982). The impact of inferential beliefs on product evaluations. Journal of Marketing Research, 19(3), 324-333. doi:10.2307/ 3151566

Hwang, I.-S., Kim, B., \& Ahn, S.-A. (2008). Economic ripple effect of Korean wave(Hallyu): Impacts of the satisfaction of Korean popular music among Chinese college students on the purchase intention for Korean culture products. The Journal of the Korea Contents Association, 8(6), 140-150. doi:10. 5392/JKCA.2008.8.6.140

Hwang, J. S. (1998). The effects of body-cathexis and importance of meeting the ideal body image on clothing benefits sought. Journal of the Korean Society of Clothing and Textiles, 22(3), 293-302.

Janis, I. L., Kaye, D., \& Kirschner, P. (1965). Facilitating effects of "eating-while-reading" on responsiveness to persuasive communications. Journal of Personality and Social Psychology, 1(2), 181-186. doi:10.1037/h0021644

Jiang, Q. \& Leung, L. (2012). Lifestyles, gratifications sought, and narrative appeal: American and Korean TV drama viewing among Internet users in urban China. International Communication Gazette, 74 (2), 159-180. doi:10.1177/1748048511432601

Jun, J. \& Zhang, X. (2012). A study on the impact processes of Korean TV dramas on the image of Korean products among Chinese audiences. International Area Studies Review, 16(2), 135-154.
Kaiser, S. B. (1997). The social psychology of clothing: symbolic appearances in context (2nd ed.). New York: Fairchild.

Karrh, J. A., McKee, K. B., \& Pardun, C. J. (2003). Practitioners' evolving views on product placement effectiveness. Journal of Advertising Research, 43(2), 138-149. doi:10.1017/S0021849903030198

Kastenholz, E. (2010). 'Cultural proximity' as a determinant of destination image. Journal of Vacation Marketing, 16(4), 313-322. doi:10.1177/ 1356766710380883

Kim, D. K., Singhal, A., Hanaki, T., Dunn, J., Chitnis, K., \& Han, M. W. (2009). Television drama, narrative engagement and audience buying behavior: The effects of winter sonata in Japan. International Communication Gazette, 71(7), 595-611. doi:10.1177/ 1748048509341894

Kim, E. A. \& Lee, M. H. (1992). Clothing image and clothing design preferences relating to personal values. Journal of the Korean Society of Costume, 18, 269-281.

Kim, J. E. \& Park, K. S. (2004). The analysis of the effects of Hanliu phenomenon on the Chinese young generation's fashion style. Journal of the Korean Society of Clothing and Textiles, 28(1), 154-164.

Kim, J. G. \& Ahn, S. Y. (2012). Hallyu's effects on exports of Korean consumption goods: A comparative study of Chinese and Vietnamese consumers. Journal of International Trade and Industry Studies, 17(3), 193-217.

Kleppe, I. A., Iversen, N. M., \& Stensaker, I. G. (2002). Country images in marketing strategies: Conceptual issues and an empirical Asian illustration. Journal of Brand Management, 10(1), 61-74. doi:10.1057/ palgrave.bm.2540102

Kuo, L. (2015, April 23). China is the world's fastestgrowing market for "vanity" spending. Quartz, Retrieved December 2, 2016, from http://qz.com/ 389469/china-is-the-worlds-fastest-growing-marke t-for-vanity-spending

Kwon, Y. J., Hong, B.-S., Seo, S., \& Cho, M.-A. 
(2009). The effects of the attributes of Korean celebrity advertising models on Chinese consumer's intention to purchase Korean fashion brands. Journal of the Korean Society of Clothing and Textiles, 33(3), 477-488. doi:10.5850/JKSCT.2009. 33.3.477

Laroche, M., Papadopoulos, N., Heslop, L. A., \& Mourali, M. (2005). The influence of country image structure on consumer evaluations of foreign products. International Marketing Review, 22(1), 96-115. doi:10.1108/02651330510581190

Lee, Y.-A. (2009). Exploratory correlation analysis among age identity, proximity of clothing to self, and self-actualization for older persons in the United States. Journal of the Korean Society of Clothing and Textiles, 33(12), 1897-1909. doi:10.5850/JK SCT.2009.33.12.1897

Lim, H.-K., Lee, J.-W., \& Kim, M. Y. (2013). The effect of Korean national image on Chinese female college student's attitude towards Korean fashion. Journal of the Korean Society of Clothing and Textiles, 37(4), 439-451. doi:10.5850/JKSCT.2013. 37.4.439

Lim, K. B., Lim, S. J., \& Jo, J. S. (1995). A study on value and clothing behavior by generation. Journal of the Korean Society of Clothing and Textiles, 19(4), 615-627.

Makela, K., Kalla, H. K., \& Piekkari, R. (2007). Interpersonal similarity as a driver of knowledge sharing within multinational corporations. International Business Review, 16(1), 1-22. doi:10.1016/ j.ibusrev.2006.11.002

McCroskey, J. C., Richmond, V. P., \& Daly, J. A. (1975). The development of a measure of perceived homophily in interpersonal communication. Human Communication Research, 1(4), 323-332. doi:10.1111 /j.1468-2958.1975.tb00281.x

Monga, A. B., \& John, D. R. (2007). Cultural differences in brand extension evaluation: The influence of analytic versus holistic thinking. Journal of Consumer Research, 33(4), 529-536. doi:10.
$1086 / 510227$

Moon, H.-J. (2014). The relationship of the Korean wave, the Korean wave contents, the product preference and country image: Focused on the international students in Korea. Advertising Research, 100, 142-171.

Mulligan, M. (2015, July 29). Chinese consumers 'laugh off' stock market gyrations. The Sydney Morning Herald, Retrieved December 2, 2016, from http://www.smh.com.au/business/china/chineseconsumers-laugh-off-stock-market-gyrations-2015 0729-gimt3d.html

Oberecker, E. M., \& Diamantopoulos, A. (2011). Consumers' emotional bonds with foreign countries: Does consumer affinity affect behavioral intentions? Journal of International Marketing, 19(2), 45-72. doi:10.1509/jimk.19.2.45

Oyunkhuu, E., \& Park, J.-H. (2015). The effects of the Korean wave, national image, and companies' image on the attitude toward Korean products and purchase intention in Mongolia. Journal of the Korean Data Analysis Society, 17(3), 1461-1473.

Parameswaran, R., \& Pisharodi, R. M. (1994). Facets of country of origin image: An empirical assessment. Journal of Advertising, 23(1), 43-56. doi:10.1080/ 00913367.1994.10673430

Petty, R. E., \& Cacioppo, J. T. (1981). Attitudes and persuasion: Classic and contemporary approaches. Boulder, Colorado: Westview Press.

Rogers, E. M. (2005). Diffusion of innovations (5th ed.). New York: Free Press.

Rogers, E. M., \& Bhowmik, D. K. (1970). Homophilyheterophily: Relational concepts for communication research. Public Opinion Quarterly, 34(4), 523-538. doi:10.1086/267838

Russo, C. (2015, Aug 13). Global Chinese consumer leaves no winners in luxury stocks. Bloomberg, Retrieved December 2, 2016, from http://www. bloomberg.com/news/articles/2015-08-12/global-c hinese-consumer-leaves-no-winners-in-luxury-stoc ks-rout 
Ryu, H.-J. (2013). Study on chinese people's cultural proximity and acceptance of Korean drama. Unpublished master's thesis. Chung-Ang University, Seoul, Korea.

Schlinger, M. J. \& Plummer, J. T. (1972). Advertising in black and white. Journal of Marketing Research, 9(2), 149-153. doi:10.2307/3149947

Shin, K.-S., \& Kim, C.-H. (2007). A study on the effects of Korea's national image in evaluation of products. International Areas Studies Review, 11 (2), 259-285.

Shrum, L. J., \& O'Guinn, T. C. (1993). Processes and effects in the construction of social reality: Construct accessibility as an explanatory variable. Communication Research, 20(3), 436-471. doi:10.1177/009 365093020003005

Simpson, E. M., Snuggs, T., Christiansen, T., \& Simples, K. E. (2000). Race, homophily, and purchase intentions and the black consumers. Psychology \& Marketing, 17(10), 877-889. doi:10.1002/1520-6793 (200010)17:10<877::AID-MAR3>3.0.CO;2-K

Su, H. J., Huang, Y.-A., Brodowsky, G., \& Kim, H. J. (2011). The impact of product placement on TVinduced tourism: Korean TV dramas and Taiwanese viewers. Tourism Management, 32(4), 805-814. doi:10.1016/j.tourman.2010.06.020

Sun, C. (2015, April 23). China tops world in 'vanity spending' growth. South China Morning Post, Retrieved December 2, 2016, from http://www. scmp.com/news/china/money-wealth/article/17738 75/china-tops-world-vanity-spending-growth

Szybillo, G. J., \& Jacoby, J. (1974). Effects of different levels of integration on advertising preference and intention to purchase. Journal of Applied
Psychology, 59(3), 274-280. doi:10.1037/h0036661

Tang, S. K. (2015, March 10). Riding the K-wave, these Korean stocks are set to soar. $C N B C$, Retrieved December 2, 2016, from http://www.cnbc.com/id/ 102487133

Van Reijmersdal, E. A., Neijens, P. C., \& Smit, E. G. (2007). Effects of television brand placement on brand image. Psychology \& Marketing, 24(5), 403-420. doi:10.1002/mar.20166

Woodside, A. G., \& Davenport, J. W. (1974). The effect of salesman similarity and expertise on consumer purchasing behavior. Journal of Marketing Research, 11(2), 198-202. doi:10.2307/3150562

$\mathrm{Xu}$, J. H. (2007). Brand-new lifestyle: Consumer-oriented programmes on Chines television. Media, Culture and Society, 29(3), 363-376. doi:10.1177/016344 3707076180

Yang, W.-D., Kim, S.-A., Rhee, Y.-S. (2012). Preference for Korean popular culture on purchase intention of Korean fashion products: Focus on the Dalian areas of China. Journal of the Korean Society of Clothing and Textiles, 36(2), 206-217. doi:10.5850/ JKSCT.2012.36.2.206

Yoo, J.-W. (2007). The effect of Korean dramas on Korea's image overseas: A study of Chinese and Japanese viewers. Journal of Public Relations, 11 (2), 126-158.

Zajonc, R. B. (1968). Attitudinal effects of mere exposures. Journal of Personality and Social Psychology, 9(2), 1-27. doi:10.1037/h0025848

Zajonc, R. B. (2001). Mere exposure: A gateway to the subliminal. Current Directions in Psychological Science, 10(6), 224-228. doi:10.1111/1467-8721.00154 